\title{
Function Based Donor/Recipient Matching in ECD Kidney Transplantation Using the Creatinine Clearance Match Ratio (CCMR)
}

\section{Jamie E Anderson and Jeffrey B Halldorson}

Department of Surgery, University of California, CA, USA

Keywords: Kidney transplantation; End-stage renal disease; Extended criteria donor; Creatinine clearance

Abbreviations: TBMI: Body Mass Index, CCMR: Creatinine Clearance Match Ratio, eCrCl: Estimated Creatinine Clearance, ECD: Expanded Criteria Donor, HR: Hazard Ratio, KDRI: Kidney Donor Risk Index, OR: Odds Ratio, SCD: Standard Criteria Donor, SRTR: Scientific Registry of Transplant Recipients

\section{Function Based Donor/Recipient Matching in ECD Kidney Transplantation}

Expanded criteria donor kidneys (ECD) have the potential to greatly increase the number of kidneys available for transplantation; however utilization is limited by poorer outcomes [1-5]. One strategy to improve outcomes and secondarily utilization is improved matching of kidneys based on recipient factors such as surface area [6,7], kidney graft size to recipient weight $[8]$ and kidney weight to recipient weight $[9,10]$. Recently our group developed the creatinine clearance match ratio (CCMR) as an improved matching technique. The CCMR is calculated using a manipulation of the Cockcroft-Gault equation estimating the creatinine clearance required by the recipient at a serum creatinine level of 1.0 thereby producing an estimated value for an individual's creatinine production and in intellectual shorthand, "nephron need" $[11,12]$. We simply asked; "how much Creatinine clearance would a potential recipient require to achieve a post-transplant serum creatinine of 1.0," and then created a variable utilizing Cockcroft-Gault estimated donor creatinine clearance from known donor variables. Simplification results in the equation below.

CCMR $=\left(140\right.$-age $\left.{ }^{\text {recepient }}\right) *\left(\text { Mass in } \mathrm{Kg}^{\text {recepient }}\right)^{\star}(0.85$ if female $) /$ $\left(140 \text {-age }{ }^{\text {donor }}\right)^{\star}\left(\mathrm{Wt} \text { in } \mathrm{Kg}^{\text {donor }}\right)^{\star}(0.85$ if female $) /\left(\right.$ Serum $\left.\mathrm{Cr} \mathrm{mg} / \mathrm{dL}^{\text {donor }}\right)$

Put simply, a high creatinine producer (numerator) matched to a donor kidney with a lower estimated creatinine clearance (denominator) produces a higher value. Conversely, a low creatinine producer (numerator) matched to a kidney with a higher estimated clearance (denominator) results in a lower value.

Briefly summarizing the findings of our study of 25,640 ECD kidney transplants: 1) multivariate analysis demonstrated higher CCMR was associated with increased graft failure and odds of requiring dialysis within the first week (comparing highest ratio quintile versus lowest ratio quintile: HR 1.43, p<0.001; OR 2.08, p<0.001) and 2) CCMR was found to be superior in prediction and discrimination ability as compared to donor creatinine clearance, recipient/donor age ratio, and recipient/donor weight ratio. To compare the utility between CCMR and other predictive strategies utilized in ECD transplantation - KDRI, weight ratio, age ratio, and recipient and donor creatinine clearances. CCMR, weight ratio, and recipient clearance were found to be statistically significant for both outcomes, whereas KDRI and age ratio were only significant for predicting graft failure. Surprisingly, estimated donor clearance alone was not found to be statistically significant in any model.

These results suggest that ECD kidneys have improved short- and long-term outcomes when the CCMR is optimized for a particular recipient/donor match. Higher CCMR was found to have worse outcomes than comparison variables, including KDRI, weight ratio, age ratio, or the donor creatinine clearance alone. In sum, both the quality of the ECD kidney and how well that kidney is matched to meet the recipient's estimated creatinine production rate optimizes many survival parameters and results in fewer recipients returning to dialysis.

The simplest explanation for our findings is that recipients with high creatinine production require dialysis earlier than low creatine producer recipients at the same level of creatinine clearance. This appears to be true both in the early post transplant period when dialysis requirement is described as delayed graft function and late when return to dialysis is graft failure.

Alternatively, recipients who receive a donor kidney with an inadequate "nephron dose" may suffer hyperfiltration syndrome and progressive kidney damage. This phenomenon has been described when a smaller kidney is transplanted into a larger recipient. Although Giral et al. found a greater adaptive increase in GFR when transplants with a lower kidney weight to recipient weight ratio during the first three months after transplantation these kidneys had worse overall graft survival [10]. Hyperfiltration injury as described results in glomeruli enlargement, hyperfiltration and ends in chronic inflammation, glomerular sclerosis, interstitial fibrosis and premature graft loss.

Similar to our study, Stratta et al. demonstrated similar outcomes in ECD kidneys compared to SCD kidneys when careful donor/ recipient need based matching was employed [13]. This group used the Cockcroft-Gault formula with actual and ideal body weight to estimate donor creatinine clearance. They deemed kidneys with estimated creatinine clearance $(\mathrm{eCrCl})>70 \mathrm{~mL} / \mathrm{min}$ acceptable for single-kidney transplantation, preferably into a recipient with a BMI $<25 \mathrm{~kg} / \mathrm{m}^{2}$. Kidneys with $\mathrm{eCrCl}<50 \mathrm{~mL} / \mathrm{min}$ were not used, while kidneys with eCrCl between $50-70 \mathrm{~mL} / \mathrm{min}$ were considered for a double kidney transplant. Under their study protocol, ECD kidneys were matched according to estimated renal functional mass and recipient need had similar outcomes to SCD kidneys.

In conclusion, our research as well as others suggests that an optimizing matching between some measure of recipient "nephron need" and "nephron dose" can improve short and long term outcomes in ECD kidney transplantation. The CCMR method based on the

*Corresponding author: Jeffrey B. Halldorson, Department of Surgery, University of California, 1200 W. Arbor Drive \#8400, San Diego, 92103, CA, USA, E-mail: jhalldorson@ucsd.edu

Received February 22, 2016; Accepted February 23, 2016; Published March 01 2016

Citation: Anderson JE, Halldorson JB (2016) Function Based Donor/Recipient Matching in ECD Kidney Transplantation Using the Creatinine Clearance Match Ratio (CCMR). Surgery Curr Res 6: e119. doi:10.4172/2161-1076.1000e119

Copyright: (C) 2016 Anderson JE, et al. This is an open-access article distributed under the terms of the Creative Commons Attribution License, which permits unrestricted use, distribution, and reproduction in any medium, provided the original author and source are credited. 
Citation: Anderson JE, Halldorson JB (2016) Function Based Donor/Recipient Matching in ECD Kidney Transplantation Using the Creatinine Clearance Match Ratio (CCMR). Surgery Curr Res 6: e119. doi:10.4172/2161-1076.1000e119

Cockcroft-Gault equation is a simple, intuitive and effective method to accomplish this goal and is an improvement as compared to placement based on donor clearance alone. Increasing the utilization of ECD kidneys depends on developing new strategies to optimize outcomes. Improved recipient/donor matching utilizing CCMR is a novel and practical tool that may facilitate progress towards this goal.

\section{References}

1. Halldorson J, Roberts JP (2013) Decadal Analysis of Deceased Organ Donation in Spain and the United States Linking an Increased Donation Rate and the Utilization of Older Donors. Liver Transpl 19: 981-986.

2. Lee CM, Carter JT, Randall HB, Hiose R, Stock PG, et al. (2000) The effect of age and prolonged cold ischemia times on the national allocation of cadaveric renal allografts. J Surg Res 91: 83-88.

3. Kasiske BL, Snyder J (2002) Matching older kidneys with older patients does not improve allograft survival. J Am Soc Nephrol 13: 1067-1072.

4. Moreso F, Seron D, Gil-Vernet S, Riera L, Fulladosa X (1999) Donor age and delayed graft function as predictors of renal allograft survival in rejection-free patients. Nephrol Dial Transplant 14: 930-935.

5. Vivas CA, O'Donovan RM, Jordan ML, Hickey DP, Hrebinko R (1992) Cadaveric renal transplantation using kidneys from donors greater than 60 years old. Clin Transplant 6: 77-80.
6. el-Agroudy AE, Hassan NA, Bakr MA, Foda MA, Shokeir AA, et al. (2003) Effect of donor/recipient body weight mismatch on patient and graft outcome in livingdonor kidney transplantation. Am J Nephrol 23: 294-299.

7. Gaston RS, Hudson SL, Julian BA, Laskow DA, Deierhoi MH, et al. (1996) Impact of donor/recipient size: matching on outcomes in renal transplantation. Transplantation 61: 383-388.

8. Miles AM, Sumrani N, John S, Markell MS, Distant DA, et al. (1996) The effect of kidney size on cadaveric renal allograft outcome. Transplantation 61: 894897.

9. Kim YS, Moon JI, Kim DK, Kim SI, Park K (2001) Ratio of donor kidney weight to recipient bodyweight as an index of graft function. Lancet 357: 1180-1181.

10. Giral M, Foucher Y, Karam G, Labrune Y, Kessler M, et al. (2010) Kidney and recipient weight incompatibility reduces long-term graft survival. J Am Soc Nephrol 21: 1022-1029.

11. Cockcroft DW, Gault MH (1976) Prediction of creatinine clearance from serum creatinine Nephron 16: 31-41.

12. Anderson J, Steiner W, Mekeel K, Chang D, Hemming A, et al (2015) ECD kidney transplantation outcomes are improved when matching donors to recipients using a novel creatinine clearance match ratio (CCMR). Clinical Transplant 29: 738-746.

13. Bosma RJ, Kwakernaak AJ (2007) Body mass index and glomerular hyperfiltration in renal transplant recipients: cross-sectional analysis and longterm impact. Am J Transplant 7: 645-652. 